УДК 614.8.084

\author{
КОМПЛЕКСНЫЙ ПОДХОД К ОБЕСПЕЧЕНИЮ \\ ПРОМЫШЛЕННОЙ БЕЗОПАСНОСТИ ПРИ СТРОИТЕЛЬСТВЕ \\ СКВАЖИН С ИСПОЛЬЗОВАНИЕМ РАСТВОРОВ \\ НА УГЛЕВОДОРОДНОЙ ОСНОВЕ
}

\title{
COMPREHENSIVE APPROACH \\ TO ENSURING INDUSTRIAL SAFETY IN WELLS CONSTRUCTION USING OIL DRILLING MUDS
}

Шириева Н.С., Шириев А.К., Тляшева Р.Р.

Филиал ООО «ЛУКОЙЛ-Инжиниринг» «КогалымНИПИнефть»

в г. Тюмени, г. Тюмень, Российская Федерация

Уфимский государственный нефтяной технический университет,

г. Уфа, Российская Федерация

N.S. Shirieva, A.K. Shiriev, R.R. Tlyasheva

KogalymNIPIneft Branch of LUKOIL-Engineering LLC in Tyumen, Tyumen, Russian Federation

Ufa State Petroleum Technological University,

Ufa, Russian Federation

e-mail: belyaevans90@gmail.com

Аннотация. Использование растворов на углеводородной основе (РУО) при бурении нефтяных и газовых скважин обуславливает необходимость внимательного отношения к вопросам промышленной безопасности. Применение растворов на углеводородной основе неизбежно приводит к увеличению воздействия вредных веществ на персонал, к повышению вероятности реализации взрыва топливно- 
воздушной смеси и росту объема хранящихся пожаровзрывоопасных веществ на буровой площадке.

Для предотвращения вредного воздействия при использовании РУО необходимо применять комплекс мер, заключающийся в соблюдении требований нормативных документов по промышленной безопасности и охране труда, обеспечении безопасных условий труда для персонала на буровой, исключении образования взрывоопасных смесей с воздухом и создании безопасных условий хранения углеводородной основы.

Мероприятиями, снижающими риск возникновения взрыва топливновоздушной смеси, является соблюдение проектных решений и требований нормативной документации - установка газоанализаторов (у ротора, в блоке приготовления раствора, у вибросит, в насосном помещении) и вентиляции. Перечень контролируемых параметров должен включать систематическое измерение температуры РУО на устье скважины и сопоставление их с температурой вспышки основы для приготовления раствора (нефти и нефтепродуктов) для исключения вероятности реализации взрыва топливно-воздушной смеси.

При этом снизить воздействие вредных веществ на персонал позволит применение технологии производства, исключающей контакт человека с вредными веществами, использование средств индивидуальной защиты и разработка паспорта безопасности на применяемый РУО. Рекомендуется также выбирать дисперсионную среду РУО с наименьшим содержанием ароматических углеводородов для минимизации вредного воздействия на персонал.

При выборе наливного оборудования необходимо учитывать особенности хранения РУО и отработанного раствора. После проведения дополнительной оценки безопасности в качестве альтернативного наливного оборудования предлагается использовать эластичные (мягкие) резервуары. 
Для получения результатов по надежности и безопасности эластичных (мягких) резервуаров, отражающих реальные условия эксплуатации, необходимо проводить механические испытания при температурах, соответствующих климатическому району при эксплуатации.

Abstract. The use of oil drilling muds (ODM) in oil and gas wells drilling necessitates careful attention to industrial safety issues. The use of oil drilling muds inevitably leads to an increase in the impact of hazardous substances on personnel, to an increase in the likelihood of an explosion of the fuel-air mixture and an increase in the volume of stored fire-hazardous substances at the well site.

To prevent the harmful effects of ODM using, it is necessary to apply a set of measures consisting in meeting the requirements of regulatory documents on industrial safety and labor protection, ensuring safe working conditions for personnel at the rig, eliminating the formation of explosive mixtures with air, and creating safe conditions for storing the hydrocarbon base.

Reducing risk Measures of fuel-air mixture explosion are compliance with the design decisions and the requirements of regulatory documents - installation of gas analyzers (at the rotor, in the solution preparation unit, at the vibrating screens, in the pump room) and ventilation. The list of monitored parameters should include a systematic measurement of the ODM temperature at the wellhead and their comparison with the flash point of the basis for the preparation of the solution (oil and oil products) to exclude the likelihood of the explosion of the fuel-air mixture.

At the same time, the use of production technology that prevents human contact with hazardous substances, the use of personal protective equipment and the development of a safety data sheet for the precautionary personnel area will reduce the impact of harmful substances on personnel. It is also recommended to choose the dispersion medium of the ODM with the lowest content of aromatic hydrocarbons to minimize the harmful effects on personnel. 
When choosing a filling equipment, it is necessary to take into account the storage peculiarities of ODM and the waste drilling mud. After conducting additional safety assessments, it is proposed to use elastic (soft) tanks as alternative filling equipment.

To obtain results on the reliability and safety of elastic (soft) tanks, reflecting the actual operating conditions, it is necessary to carry out mechanical tests at temperatures appropriate to the climatic region during operation.

Ключевые слова: промышленная безопасность, раствор на углеводородной основе, идентификация опасностей, эластичный (мягкий) резервуар

Key words: industrial safety, oil drilling mud, identification of hazards, collapsible fabric fuel tank

При строительстве нефтяных и газовых скважин для конкретных условий бурения применяются растворы на углеводородной основе (РУО). Если сравнивать РУО и буровые растворы на водной основе (PBO), то первые имеют ряд преимуществ: способствуют поддержанию естественной продуктивности пласта, обладают высокой термостойкостью и антикоррозийными свойствами, мало диспергируют выбуренные породы, предотвращают гидратацию глинистых пород. В связи с этим происходит минимизация возможности возникновения осложнений, повышается качество вскрытия продуктивных пластов.

На месторождениях ООО «ЛУКОЙЛ-Западная Сибирь» РУО применяют при зарезке боковых стволов, при строительстве многозабойных скважин и бурении на депрессии. Количество скважин, пробуренных с использованием РУО с 2009 года, представлено на рисунке 1. 


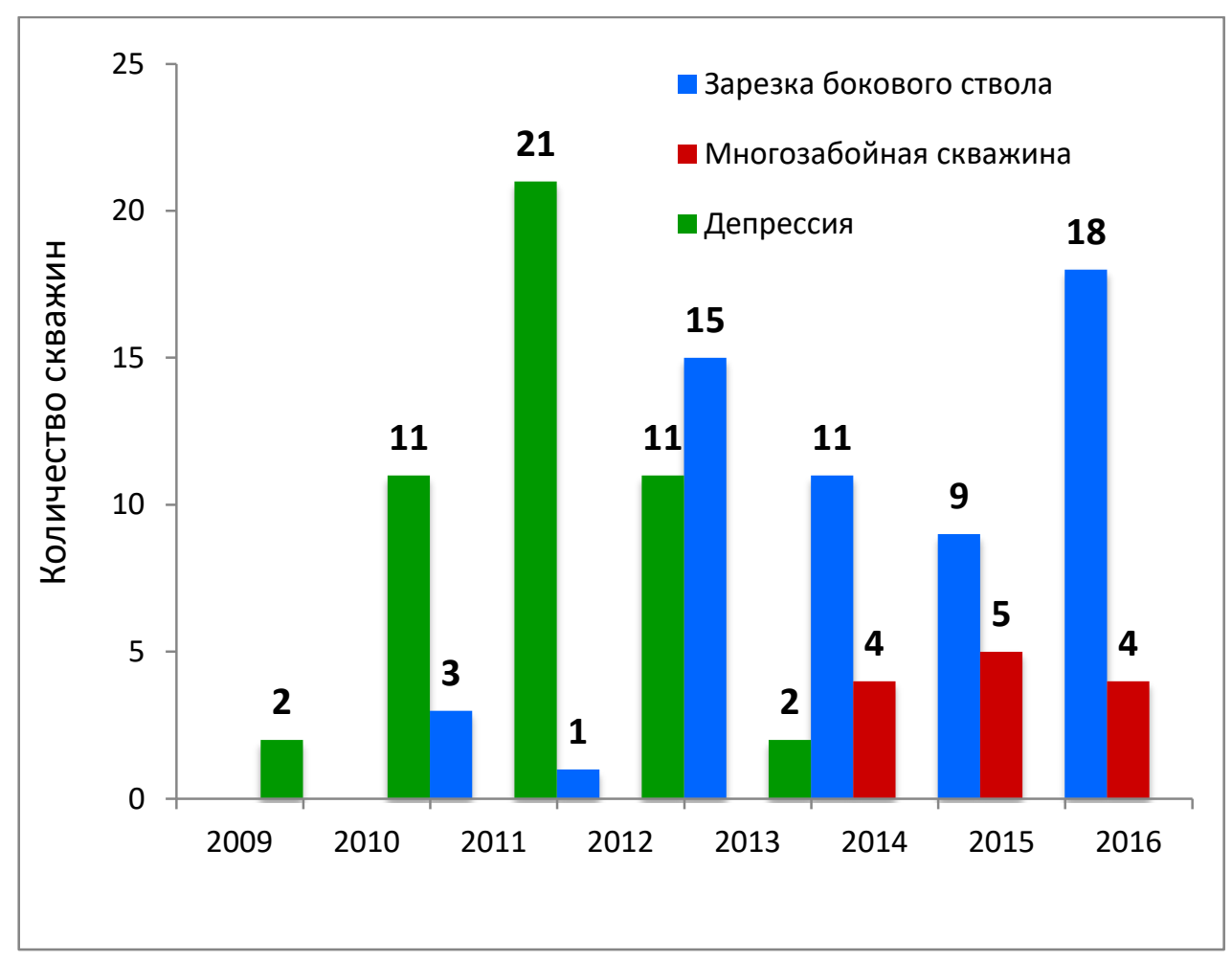

Рисунок 1. Количество скважин, пробуренных с использованием РУО

Представленный обзор о применении РУО в практике бурения нефтяных и газовых скважин свидетельствует о совершенствовании их рецептур в части технологичности и сохранности коллекторских свойств продуктивных пластов. Однако существует и ряд существенных минусов, которые оказывают тормозящее действие на тенденцию их использования, а именно: высокая стоимость дисперсионной среды (минерального масла, дизельного топлива, нефти), медленное и неполное биоразложение, значительная токсичность [1], трудности при удалении с инструмента и оборудования, а также их пожаровзрывоопасность.

Буровые растворы на углеводородной основе подразделяются на практически безводные и гидрофобно-эмульсионные [2]. Безводные (практически безводные) РУО представляют собой многокомпонентную систему, в которой дисперсионной (несущей) средой является нефть или жидкие нефтепродукты (обычно дизельное топливо, нефть или минеральное масло), а дисперсной фазой - окисленный битум, асфальт или специально обработанная глина (гидрофобизированный бентонит). 
Международной ассоциацией представителей нефтегазовой промышленности по экологическим и социальным вопросам (IPIECA) и Международной ассоциацией производителей нефти и газа (OGP) РУО классифицируются на 3 группы по содержанию ароматических углеводородов [3] (таблица 1).

Таблица 1. Классификация растворов на углеводородной основе по содержанию ароматических углеводородов

\begin{tabular}{|l|l|l|}
\hline \multicolumn{1}{|c|}{ Группа } & \multicolumn{1}{|c|}{ Компонентный состав } & \multicolumn{1}{|c|}{$\begin{array}{l}\text { Содержание } \\
\text { ароматических } \\
\text { углеводородов }\end{array}$} \\
\hline $\begin{array}{l}\text { Группа I - высокое содержание } \\
\text { ароматических углеводородов }\end{array}$ & $\begin{array}{l}\text { Сырая нефть, дизельное топливо и } \\
\text { обычные минеральные масла }\end{array}$ & $5-35 \%$ \\
\hline $\begin{array}{l}\text { Группа II - среднее содержание } \\
\text { ароматических углеводородов }\end{array}$ & Низкотоксичное минеральное масло & $0,5-5 \%$ \\
\hline $\begin{array}{l}\text { Группа III - } \\
\text { низкое/несущественное } \\
\text { содержание ароматических } \\
\text { углеводородов }\end{array}$ & $\begin{array}{l}\text { Сложноэфирные соединения, олефины, } \\
\text { изомеризованные олефины, } \\
\text { полиальфаолефины, неразветвленные } \\
\text { парафины и с высокой степенью } \\
\text { переработки минерального масла }\end{array}$ & $\begin{array}{l}<0,5 \% \text { и } \\
\text { полициклических } \\
\text { ароматических } \\
\text { углеводороды } \\
\text { ниже 0,001 \% }\end{array}$ \\
\hline
\end{tabular}

Ароматические углеводороды оказывают наибольшее вредное воздействие на организм человека, высокое содержание ароматических углеводородов может угрожать хроническими отравлениями с изменениями крови и кроветворных органов [4]. Поэтому при прочих равных технических характеристиках дисперсионной среды РУО рекомендуется выбирать группу с наименьшим содержанием ароматических углеводородов для минимизации вредного воздействия на персонал. К примеру, при выборе нефти в качестве дисперсионной среды рекомендуется использовать метановые или нафтеновые, либо метанонафтеновые типы нефти.

Основным нормативным документом, касающимся вопросов безопасности при строительстве скважин, являются Федеральные нормы и правила «Правила безопасности в нефтяной и газовой промышленности» [5]. В п. 219-220 главы XVII «Требования безопасности к применению буровых растворов» определено, что буровым подрядчиком должны быть 
разработаны мероприятия по охране труда по предупреждению загрязнения рабочих мест и загазованности воздушной среды при применении буровых растворов на углеводородной основе, также прописано требование, что температура вспышки $\mathrm{PУO}$ должна на $50{ }^{\circ} \mathrm{C}$ превышать максимально ожидаемую температуру раствора на устье скважины [5]. Таким образом, должно быть предусмотрено измерение температуры РУО на устье скважины. Пары раствора на выходе из скважины, нагретого до температуры выше или равной его температуре вспышки, при наличии источника зажигания, способны вспыхивать в воздухе, что, в свою очередь, может привести к взрыву. Перечень контролируемых параметров обязательно должен включать систематическое измерение температуры РУО на устье скважины и сопоставление их с температурой вспышки основы для приготовления раствора - нефти и нефтепродуктов.

Необходимо отметить, что в «Правилах...» [5] отсутствуют требования к системе приготовления и циркуляции РУО, в том числе нет требований к использованию закрытой циркуляционной системы при бурении на депрессии.

Рецептура РУО выбирается на этапе разработки проекта на строительство скважин. Одновременно с этим, обязательным условием на этапе разработки проектной документации является анализ степени риска, в результате которого должна быть определена достаточность технологических решений, обеспечивающих безопасное ведение процесса бурения.

На ранних стадиях разработки проектной документации рекомендуется в ходе проведения анализа риска применять метод «Идентификация опасностей». Основными задачами метода являются [6]:

- выявление источников опасностей и определение последствий их реализации посредством анализа опасного производственного объекта (ОПО) и его составных частей с учетом особенностей технологии, 
инфраструктуры, площадки размещения, окружающей местности и расположения иных объектов;

- описание выявленных опасностей и рекомендаций для использования их в последующих работах по анализу риска аварий и т.д.

В результате идентификации опасностей выявлено, что использование РУО неизбежно приводит к увеличению воздействия вредных веществ на персонал, повышению вероятности реализации взрыва топливновоздушной смеси и росту объема хранящихся пожаровзрывоопасных веществ на буровой.

Для более детального рассмотрения опасностей при использовании РУО на рисунке 2 представлена технологическая схема циркуляции раствора с указанием блоков, где возможно образование топливновоздушных смесей.

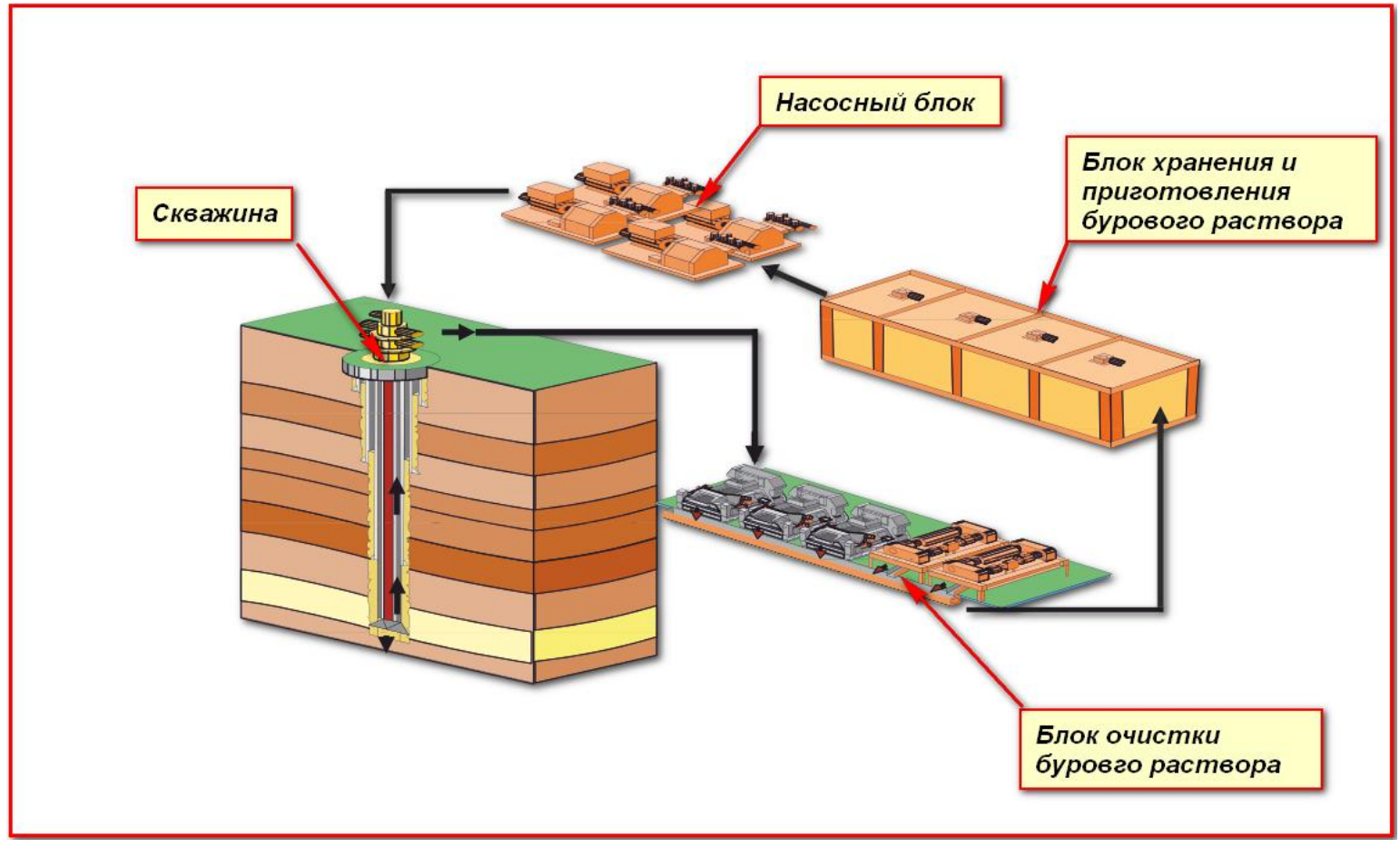

Рисунок 2. Схема циркуляции РУО с указанием блоков, где возможно образование топливно-воздушных смесей

Образование взрывоопасных смесей может происходить в ходе технологических процессов либо являться основным или побочным 
продуктом самого производства. Испарение углеводородов возможно в блоке приготовления и хранения РУО, блоке очистки бурового раствора, на линии от устья скважины до блока очистки. Соответственно, возможно образование взрывоопасных концентраций с кислородом и при наличии источника зажигания - взрыв топливно-воздушной смеси.

Температура бурового раствора, скорость потока, кинематическая вязкость влияют на образование углеводородных паров (аэрозоля, нефтяного тумана). На сегодняшний день не проводились исследования о влиянии пластовых флюидов на компонентный состав РУО и образование углеводородных паров (аэрозолей, туманов). Кроме этого, экраны вибросит являются своеобразными «генераторами» углеводородных паров (аэрозолей), которые содержат не только легкие, но и тяжелые фракции РУО, а их концентрация напрямую зависит от температуры.

Обязательными мероприятиями, снижающими риск возникновения взрыва топливно-воздушной смеси, являются строгое соблюдение проектных решений и требований нормативных документов по промышленной безопасности (установка газоанализаторов у ротора, в блоке приготовления раствора, у вибросит, в насосном помещении и вентиляции).

В соответствии с требованием п. 2.2 ГОСТ 12.1.007-76 [7] мероприятия по обеспечению безопасности труда при контакте с вредными веществами должны предусматривать: применение прогрессивной технологии производства (замкнутый цикл, автоматизация, комплексная механизация, дистанционное управление, непрерывность процессов производства, автоматический контроль процессов и операций), исключающей контакт человека с вредными веществами; включение данных токсикологических характеристик вредных веществ в технологические регламенты; применение средств индивидуальной защиты работающих.

При этом снизить воздействие вредных веществ на персонал позволит применение технологии производства, исключающей контакт человека с 
вредными веществами, использование средств индивидуальной защиты и разработка паспорта безопасности на применяемый РУО.

В связи с вышеизложенным предлагаются мероприятия (таблица 2) для минимизации вредного воздействия на персонал и снижения вероятности взрыва топливно-воздушной смеси при использовании РУО, которые можно рекомендовать для включения в проектную документацию на строительство скважин и для выполнения буровым подрядчиком.

Таблица 2. Мероприятия, направленные на минимизацию вредных воздействий на персонал

\begin{tabular}{|c|c|c|c|}
\hline Блок & Операция & Последствия & Мероприятия \\
\hline \multirow{2}{*}{$\begin{array}{l}\text { Блок } \\
\text { приготовления } \\
\text { раствора }\end{array}$} & $\begin{array}{l}\text { Введение } \\
\text { компонентов }\end{array}$ & $\begin{array}{l}\text { Образование пыли и } \\
\text { брызг }\end{array}$ & Автоматизированная система \\
\hline & $\begin{array}{l}\text { Перемешивание } \\
\text { компонентов }\end{array}$ & $\begin{array}{l}\text { Образование } \\
\text { углеводородных } \\
\text { паров }\end{array}$ & $\begin{array}{lr}\text { Использование } & \text { средств } \\
\text { индивидуальной } & \text { защиты } \\
\text { (СИЗ) } & \\
\text { Контроль за } & \text { состоянием } \\
\text { воздушной среды } & \end{array}$ \\
\hline $\begin{array}{ll}\text { Линия } & \text { от } \\
\text { достья } \\
\text { очистки } & \\
\text { блока }\end{array}$ & $\begin{array}{l}\text { Открытая система } \\
\text { циркуляции }\end{array}$ & $\begin{array}{l}\text { Образование } \\
\text { опасных } \\
\text { концентраций } \\
\text { углеводородных } \\
\text { паров }\end{array}$ & $\begin{array}{ll}\text { Закрытая } & \text { система } \\
\text { циркуляции }\end{array}$ \\
\hline Блок очистки & $\begin{array}{l}\text { Чистка и смена } \\
\text { экранов вибросит, } \\
\text { проверка их на } \\
\text { предмет износа }\end{array}$ & $\begin{array}{l}\text { Образование паров и } \\
\text { опасных } \\
\text { концентраций } \\
\text { углеводородов }\end{array}$ & $\begin{array}{l}\text { Использование } \\
\text { (респиратор, пИЗ } \\
\text { перчатки, нерезиненные } \\
\text { костюм) } \\
\text { Контроль за сомокаемый } \\
\text { воздушной среды } \\
\text { Вентиляция }\end{array}$ \\
\hline $\begin{array}{l}\text { Рабочая емкость } \\
\text { перед входом в } \\
\text { буровой насос } \\
\text { или на выходе из } \\
\text { системы очистки }\end{array}$ & $\begin{array}{l}\text { Отбор проб для } \\
\text { тестирования РУО }\end{array}$ & $\begin{array}{l}\text { Образование паров и } \\
\text { опасных } \\
\text { концентраций } \\
\text { углеводородов }\end{array}$ & $\begin{array}{l}\text { Использование СИЗ } \\
\text { Контроль за состоянием } \\
\text { воздушной среды }\end{array}$ \\
\hline
\end{tabular}

Процесс приготовления РУО происходит непосредственно на буровой площадке, для этого завозится основа (нефть, продукты ее переработки) для его приготовления. По окончании процесса бурения РУО подвергают очистке от выбуренной породы, далее отработанный раствор откачивают в 
дополнительные емкости для хранения, как правило, с целью дальнейшего (повторного) использования. Хранение основы раствора и отработанный раствор необходимо осуществлять в соответствии с СП 155.13130.2014 [8].

Основа для приготовления и отработанный раствор должны храниться в расходном складе, т.к. объем веществ, как правило, не превышает $2000 \mathrm{~m}^{3}$. Для этого используют металлические резервуары или пластиковую тару. При выборе наливного оборудования необходимо учитывать особенности хранения РУО и отработанного раствора. Независимо от выбора варианта хранения к расходным складам предъявляются требования по пожарной безопасности (в части противопожарных расстояний, организации обвалования по периметру, хранение под навесом или в помещении). Для приготовления раствора жидкие реагенты (основа раствора) должны быть разогреты до $+30 \ldots 50{ }^{\circ} \mathrm{C}$ для снижения вязкости и увеличения скорости диспергирования. В процессе хранения отработанного РУО в наливном оборудовании остаются твердые отложения (шлам), который необходимо удалять с соблюдением всех требований безопасности. Кроме этого, наличие в отработанном РУО коррозионно-активных примесей пластовых флюидов может привести к потере герметичности емкости и разливу нефти и нефтепродуктов, а повышение температуры может увеличить скорость коррозии металла на несколько порядков.

Обеспечить безопасные условия хранения РУО, учитывая все вышеперечисленные особенности, можно при использовании эластичных (мягких) резервуаров. Эластичные (мягкие) резервуары не подвергаются коррозионным воздействиям, имеют возможность зачистки от отложений через сборно-разборный угол, подогрев продукта внутри эластичного резервуара осуществляется специальным нагреваемым пологом при помощи электрического саморегулирующегося нагревательного кабеля. Заполнение резервуаров отработанной углеводородной жидкостью может осуществляться посредством термопластичных рукавов. 
На сегодняшний день эластичные (мягкие) резервуары не применялись для хранения РУО, поэтому предлагается провести дополнительную оценку их безопасности.

Система испытаний, которую осуществляют производители эластичных (мягких) резервуаров, позволяет оценить их по отдельным показателям в условиях, значительно отличающихся от условий эксплуатации. Объекты строительства скважин ООО «ЛУКОЙЛ-Западная Сибирь» находятся в $\mathrm{I}_{1}, \mathrm{I}_{2}, \mathrm{II}_{4}$ климатических районах (по ГОСТ 16350 [9]), которые характеризуются как очень холодный, холодный и умеренно холодный. Для получения результатов по надежности и безопасности эластичных (мягких) резервуаров испытания необходимо проводить при температурах, соответствующих климатическому району при эксплуатации, позволяющих установить закономерности изменения физико-механических свойств материала на различных стадиях жизненного цикла.

\section{Выводы и рекомендации}

Целесообразно применять комплексный подход для обеспечения промышленной безопасности при строительстве скважин с использованием РУО, включающий в себя соблюдение требований нормативных документов по промышленной безопасности, обеспечение безопасных условий труда, исключение образования взрывоопасных смесей с воздухом и обеспечение безопасных условий хранения РУО.

Мероприятиями, снижающими риск возникновения взрыва топливновоздушной смеси, является соблюдение проектных решений и требований нормативной документации - установка газоанализаторов (у ротора, в блоке приготовления раствора, у вибросит, в насосном помещении) и вентиляции. Перечень контролируемых параметров должен включать систематическое измерение температуры РУО на устье скважины и сопоставление их с температурой вспышки основы для приготовления 
раствора (нефти и нефтепродуктов) для исключения вероятности реализации взрыва топливно-воздушной смеси.

При этом снизить воздействие вредных веществ на персонал позволит применение технологии производства, исключающей контакт человека с вредными веществами, использование средств индивидуальной защиты и разработка паспорта безопасности на применяемый РУО. Рекомендуется также выбирать дисперсионную среду РУО с наименьшим содержанием ароматических углеводородов для минимизации вредного воздействия на персонал.

При выборе наливного оборудования необходимо учитывать особенности хранения РУО и отработанного раствора. После проведения дополнительной оценки безопасности в качестве альтернативного наливного оборудования предлагается использовать эластичные (мягкие) резервуары.

Для получения результатов по надежности и безопасности эластичных (мягких) резервуаров, отражающих реальные условия эксплуатации, необходимо проводить механические испытания при температурах, соответствующих климатическому району при эксплуатации.

\section{Список используемых источников}

1. Сушкова А.В. Разработка низкотоксичного и биоразлагаемого бурового раствора на основе олигомеров этилена: дисс. ... канд. техн. наук. М.: РГУ им. И.М. Губкина, 2005. 191 с.

2. Булатов А.И., Макаренко П.П., Проселков Ю.М. Буровые промывочные и тампонажные растворы. М.: Недра, 1999. 424 с.

3. A Guide for Drilling Personnel, Managers and Health Professionals in the Oil and Gas Industry. Drilling Fluids and Health Risk Management / This Document was Prepared on Behalf of the OGP/IPIECA Health Committee by the Drilling Fluids Task Force. IPIECA/OGP 2009. 27 p. 
4. Вредные вещества в промышленности: справочник / Под общ. ред. Н.В. Лазарева. Л.: Химия, 1976. 592 с.

5. Российская Федерация. Федеральная служба по экологическому, технологическому и атомному надзору. Федеральные нормы и правила в области промышленной безопасности. Правила безопасности в нефтяной и газовой промышленности. Утв. Приказом Федеральной службы по экологическому, технологическому и атомному надзору от 10.03.2015 г. № 101 .

6. Руководство по безопасности. Методические основы по проведению анализа опасностей и оценки риска аварий на опасных производственных объектах. Утв. Приказом Федеральной службы по экологическому, технологическому и атомному надзору от 11.04.2016 г. № 144.

7. ГОСТ 12.1.007-76. Вредные вещества. Классификация и общие требования безопасности. Введ. 01.01.1977. М.: Стандартинформ, 2007.

8. СП 155.13130.2014. Склады нефти и нефтепродуктов. Требования пожарной безопасности. Введ.01.02.2014. М.: МЧС России, 2014.

9. ГОСТ 16350-80. Районирование и статистические параметры климатических факторов для технических целей. Введ. 01.07.1981. М.: Изд-во стандартов, 1986.

\section{References}

1. Sushkova A.V. Razrabotka nizkotoksichnogo $i$ biorazlagaemogo burovogo rastvora na osnove oligomerov etilena: diss. kand. tekhn. nauk [Development of a Low-Toxic and Biodegradable Drilling Mud Based on Ethylene Oligomers: Cand. Engin. Sci. Diss.]. Moscow, Gubkin Russian State University of Oil and Gas, 2005. 191 p. [in Russian].

2. Bulatov A.I., Makarenko P.P., Proselkov Yu.M. Burovie promivochnie $i$ tamponajnie rastvori [Drilling Mud and Slurry Solutions]. Moscow: Nedra Publ., 1999. 424 p. [in Russian]. 
3. A Guide for Drilling Personnel, Managers and Health Professionals in the Oil and Gas Industry. Drilling Fluids and Health Risk Management. This document was prepared on behalf of the OGP/IPIECA Health Committee by the Drilling Fluids Task Force.IPIECA/OGP 2009. 27 p.

4. Vrednie veschestva v promishlennosti: spravochnik. [Harmful Substances in Industry: Handbook]. Ed. by N.V. Lazarev. Chemistry Publ., 1976. 592 p. [in Russian].

5. Rossiiskaya Federaciya. Federalnaya slujba po ekologicheskomu_ tehnologicheskomu i atomnomu nadzoru. Federalnie normi i pravila v oblasti promishlennoi bezopasnosti. Pravila bezopasnosti $v$ neftyanoi $i$ gazovoi promishlennosti. Utv. prikazom Federal'noi sluzhby po ekologicheskomu, tekhnologicheskomu i atomnomu nadzoru ot 10.03.2015 g. № 101. [Russian Federation. Federal Service for Environmental, Technological and Nuclear Supervision. Federal Rules and Regulations in the Field of Industrial Safety. Safety Rules in the Oil and Gas Industry. Approved by Order of the Federal Service for Ecological, Technological and Nuclear Supervision dd. March 10, 2015 No. 101] [in Russian].

6. Rukovodstvo po bezopasnosti. Metodicheskie osnovy po provedeniyu analiza opasnostei $i$ otsenki riska avarii na opasnykh proizvodstvennykh ob"ektakh. Utv. prikazom Federal'noi sluzhby po ekologicheskomu, tekhnologicheskomu i atomnomu nadzoru ot 11.04.2016 g. № 144 [Safety Manual. Methodological Framework for Conducting Hazard Analysis and Risk Assessment of Accidents at Hazardous Production Facilities. Approved by Order of the Federal Service for Ecological, Technological and Nuclear Supervision dd. April 11, 2016 No. 144]. [in Russian].

7. GOST 12.1.007-76. Vrednie veschestva. Klassifikaciya $i$ obschie trebovaniya bezopasnosti. Vved. 01.01.1977 [State Standard 12.1.007-76. Occupational Safety Standards System. Noxious Substances. Classification and General Safety Requirements. Intr. 01.01.1997]. Moscow, Standartinform Publ., 2007. [in Russian]. 
8. SP 155.13130.2014. Skladi nefti i nefteproduktov. Trebovaniya pojarnoi bezopasnosti. Vved. 01.02.2014 [SP 155.13130.2014. Warehouses of Oil and Oil Products. Fire Safety Requirements. Intr. 01.02.2014]. Moscow, Russian Emergency Situations Ministry, 2014. [in Russian].

9. GOST 16350-80. Raionirovanie i statisticheskie parametri klimaticheskih faktorov dlya tehnicheskih celei. Vved. 01.07.1981. [State Standard 16350-80. Zoning and Statistical Parameters of Climatic Factors for Technical Purposes. Intr. 01.07.1986]. Moscow, Publishing house of standards, 1986. [in Russian].

\section{Сведения об авторах}

\section{About the authors}

Шириева Н.С., аспирант кафедры «Пожарная и промышленная безопасность», ФГБОУ ВО «УГНТУ», г. Уфа, Российская Федерация, инженер 2 категории Отдела проектирования строительства и реконструкции скважин, Филиал ООО «ЛУКОЙЛ-Инжиниринг» «КогалымНИПИнефть» в г. Тюмени, г. Тюмень, Российская Федерация

N.S. Shirieva, Postgraduate Student of Fire and Industrial Safety Department, FSBEI HE «USPTU», Ufa, Russian Federation, Engineer of the 2nd Category, the KogalymNIPIneft Branch of LUKOIL-Engineering LLC in Tyumen, Tyumen, Russian Federation

e-mail: belyaevans90@gmail.com 
Шириев А.К., аспирант кафедры «Технологические машины и оборудование», ФГБОУ ВО «УГНТУ», г. Уфа, Российская Федерация, инженер 2 категории отдела обустройства нефтяных и газовых месторождений филиала ООО «ЛУКОЙЛ-Инжиниринг» «КогалымНИПИнефть» в г. Тюмени, г. Тюмень, Российская Федерация

A.K. Shiriev, Postgraduate Student of Technological Machinery and Equipment Department, FSBEI HE «USPTU», Ufa, Russian Federation, Engineer of the 2nd Category of the KogalymNIPIneft Branch of LUKOILEngineering LLC in Tyumen, Tyumen, Russian Federation

e-mail: arturshiriev@gmail.com

Тляшева P.P., д-р техн. наук, профессор кафедры «Технологические машины и оборудование», ФГБОУ ВО «УГНТУ», Уфа, Российская Федерация

R.R. Tlyasheva, Doctor of Engineering of Sciences, Professor of Technological Machinery and Equipment Department, FSBEI HE «USPTU», Ufa, Russian Federation

e-mail: mfugntu@mail.ru 